\title{
Towards Improving Senior High School Students' Conceptual Understanding of System of Two Linear Equations
}

\author{
Robert Akpalu ${ }^{1}$, Samuel Adaboh ${ }^{2}$, Samuel S. Boateng ${ }^{3}$
}

\section{ARTICLE INFO}

Article History:

Received 08.08.2017

Received in revised form

09.10.2017

Accepted

Available online 01.01.2018

\begin{abstract}
This study basically focused on the use of algebraic tiles to improve Senior High School (SHS) students' conceptual understanding of a system of two linear equations at St. Mary's Seminary Senior High School, Lolobi in the Volta Region of Ghana. The test instrument used for the data collection was an achievement test with eight essay type questions, with an internal consistency reliability of 0.78 . The simple random sampling technique was used to assign 70 SHS two students equally to experimental and control groups. The two groups were pre- and post-tested in the study. A pairedsample t-test was used to analyze the data. The results showed that even though there was some improvement in the posttest across the board (both control and experimental groups), there was a statistically significant improvement in the experimental group which received the intervention for four w eeks using the algebraic tiles.
\end{abstract}

(C) 2018 IJERE. All rights resenved

Keywords:

Algebraic tiles, System of linear equations, Algebraic expression.

\section{INTRODUCTION}

There is a general agreement among all stakeholders in education that every child should study mathematics at school; indeed, the study of mathematics is regarded by most people as being essential (Cockcroft, 1982; NCTM, 2000). In Ghana, mathematics is made not only compulsory at the basic school level but also mandatory at the Senior High School level. This is to ensure that all students are mathematically empow ered to further their studies without any impediment and pursue programmes of their choice (Fletcher, 2005).

How ever, in the past three decades, there have been growing concerns about falling standards of students' achievements in mathematics at both national and international levels (Blum 2002; Törner and Sriraman 2006). Research by Eshun (2004) and Eshun-Famiyeh (2005), have also shown that mathematics continues to be perceived as the most difficult subject in the school curriculum; this general perception is reflected in students' performance over the years. For example, a Criterion Reference Test (CRT) conducted in 1996 and 2000 established that only $1.8 \%$ and $4.4 \%$ of primary six students nationwide obtained a mark of 55\% respectively (MoE, 2002). "Between 1999 and 2008, a total of 905,102 candidates sat for the SSSCE/W ASSCE. Out of that number, only 88,590 representing $9.8 \%$ passed to further their education at the tertiary level. The trend has not been any different from the subsequent years, 2009-2015. In 2014, only 28\% passed(A1-C6) and despite the increase in the number of candidates in 2015, the number of candidates qualifying dropped to 25\%"' (Gavor, 2015).

It is also on record that Ghana has never been represented since 1953 in any International Mathematics Olympiad (IMO) which is an annual mathematics competition that is organized for preuniversity teams from all over the world. It is also disappointing to note that even in sub-Saharan Africa; representation at this prestigious international competition is woefully inadequate (Amponsah, 2010). In the 2003 TIMSS (Trends In International Mathematics and ScienceStudy) mathematics test for

1 Department of Mathematics and Science Education, Valley View University, Oyibi Campus, P. O. Box AF 595, Adentan-Accra, Ghana rakpalu@vvu.edu.gh, orcid.org/0000-0003-0494-6074 2 Department of Arts and Social Studies, Valley View University, Oyibi Campus, P. O. Box AF 595, Adentan-Accra, Ghana samueladaboh@vvu.edu.gh, +233554831326

3 Department of Accounting and Management Studies, Valley View University, Oyibi Campus, Accra, P. O. Box AF 595, Adentan-Accra, Ghana dr.ssboateng@vvu.edu.gh, +233242045284 
grade eight students, it was reported that out of the 45 countries that participated in the competition, Ghana finished $44^{\text {th }}$. Ghanaian students scored a total of 276 compared to the international average of 466 (Anamuah Mensah et al., 2005; Fredua-Kw arteng, 2005).

These are indications that all is not well with us as a nation (Ghana) in terms of mathematics achievement at the pre-university level. Among the challenges facing our educational institutions today are how to improve effectively on lesson delivery using appropriate teaching and learning materials, as well as how to teach students with diverse abilities such as visual, auditory, reading/writing, and kinesthetic learners. To overcome these challenges, a variety of teaching and learning strategies have been advocated for use in mathematics classrooms. Among them are educators moving away from the teacher-centered approach to more students-centred ones, and the use of concrete materials. Also, there is substantial evidence of research done by other researchers on the various effects of the use of concrete learning materials on students (Lira \& Ezeife, 2008; Kosko \& Wilkins, 2010) research since they are substantial). Mathematics teachers are constantly considering various ways of improving their teaching and helping students to understand mathematical concepts. Researchers hold the view that mathematics instructions and students' understanding are more effective if concrete materials are used (Steedly et al. 2008). However, Maslen (2014), warns that concrete materials are potentially harmful if used improperly, especilly in vulnerable educational settings where such misappropriation can lead to falling stadnards of academic perfomance (Afach, Kiw an, \& Semaan, 2018). Improperly used concrete materials are likely to convince students that two mathematical w orlds exist: concrete materials and symbolic (Milgram \& Wu 2008). Concrete materials must be relevant to the concept being developed and appropriate for the cognitive development level of students thus the utility of concrete materials in conveying mathematical concept is deeply rooted in the teachers' ability to select, organize and make appropriate linkages (Post,1981).

Concrete materials are regarded as a way of increasing mathematical understanding (Lee, 2014). They are typically real-life objects that are used to represent mathematical concepts (Kosko \& Wilkins 2010). Teachers' utilize them to clarify abstract mathematical concepts that ordinarily may be difficult for students, such as adding and subtracting integers, solving inequalities and simplifying algebraic expressions (Lira \& Ezeife, 2008). The learning process involves transitioning from manipulating concrete material to creating images from the student's perception of concept and finally, to the development or adoption of some form of symbolic notation representing the concept (Ameron et al. 2011).

However, the mathematical research literature has revealed the importance of concept formation as a powerful tool for promoting teaching and learning of mathematics. As such, theoretical approaches to the teaching and learning of mathematical concepts should give way to practical activities that promote and facilitate easy learning. Duman and Karagöz(2016) rightly pointed out that the usefulness of educational systems and concepts are enshrined in the competence of teachers who organize, plan, and moderate teaching and learning process. It could, therefore, be seen that any current reform made in the field of mathematics education is deeply rooted in finding ways of empowering students to learn to do mathematics in a more simple and practical way (Franser, 2013).

If Ghana is to achieve the Sustainable Development Goals (SDGs) and go beyond to attain the status of a successful knowledge-based economy, then she must ensure that her youth are equipped with stronger mathematical skills that include practical problem-solving skills at the pre-tertiary level. The researchers, therefore, are of the view that the traditional method of teaching mathematics is too "imposing" and "intimidating" which could only lead to a total dependency on the teacher. Teachers of mathematics should have positive attitudes toward teaching and learning of the subject by employing globalized approaches in the teaching and learning profession (Demirtas \& Aksoy, 2015). therefore, use a lot of alternative strategies including the use of concrete learning materials, to make the teaching of mathematics more practical for easy understanding. This will not only reduce the cognitive load of the students but also make mathematics learning enjoyable and stress-free.

As stated earlier, students' understanding of algebraic expressions serves as the basis for learning other kinds of equations such as linear, quadratic and simultaneous equations. Therefore, the teaching of simple algebraic expressions must be handled with care. Algebra as a topic is more concerned with the study of processes and basic structures than with particular answers to problems. 
It is in this light that the researchers decided to make relentless efforts to identify the problems faced by students in the solving system of two linear equations and use algebraic tiles to teach the students to overcome their challenges in one of the less endowed schools in Ghana, the Lolobi St. Mary's Senior High School. Despite the availability of qualified mathematics tutors and some appreciable level of logistics regarding teaching and learning materials, form two students of St. Mary's Seminary Senior High School have difficulties in deducing mathematical statements from word problems and how to use the substitution method to solve a system of two linear equations. The overall purpose of this study, therefore, was to improve these Senior High School students' conceptual understanding of the system of two linear equations using algebraic tiles.

The research hypothesis designed to direct and guide the study is:

Null hypothesis $\boldsymbol{H}_{\mathbf{0}}$ : There is no significant difference in the mean scores of students before and after introduction of Algebraic tiles in solving system of two linear equations.

\section{i. e. $\quad H_{0}: \mu_{1}=\mu_{2}$}

Alternate hypothesis is $\boldsymbol{H}_{\boldsymbol{a}}$ : There is a significant difference in the pre-test and post-test scores of students after introduction of Algebraic tiles in solving system of two linear equations (at $\alpha=0.05$ level of significance $(\mathrm{P}<0.05))$.

$$
\boldsymbol{H}_{\boldsymbol{a}}: \mu_{1} \neq \mu_{2}
$$

Any research which is aimed at improving students' conceptual understanding would go a long way to improve the quality of mathematics education. The researchers are of the view that this research would serve as an eye-opener to some teachers (and a reminder to others) to know the type of concrete materials they need to use to help students who are having difficulty in understanding how to solve a system of linear equations.

\section{Algebraic tiles in system of equation}

According to Austin (2008), a system of linear equations consists of two or more equations with the same variables. To solve a system of equations with two or more variables, there is the need to find the ordered pair that satisfies all of the equations. We can solve a system of linear equations by using an algebraic method called substitution. This method can be modelled using algebraic tiles. From the diagram below, a rectangular shape tile represents an " $x$ " variable; while " $y$ " represents a circular shape tile, and the square tile represents a constant. However, a change in colour (black) of the above tiles represents negatives.

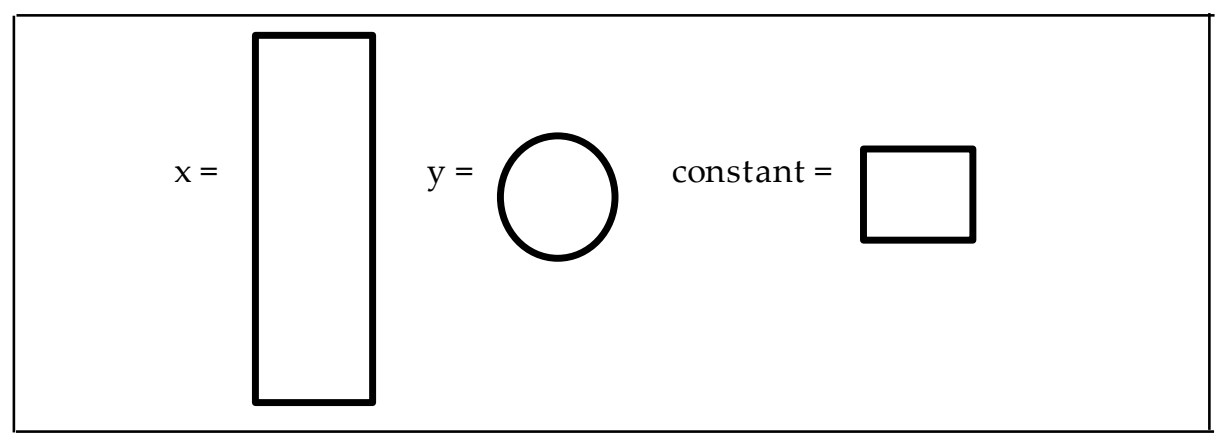

Figure 1: Alternative models for solving system of equations

Manipulative materials are concrete models or objects that involve mathematics concepts. The most effective tools are the ones that appeal to several senses, and that can be touched and moved around by students (Heddens, 1997). Some of these models are; Cuisenaire Rods, pattern blocks and snap cards.

\section{Cuisenaire Rods:}

They are coloured wooden or plastic rods that have values from one to ten and are coloured by the number they represent. For example White $\operatorname{rod}=1$, Red $\operatorname{rod}=2$, Light green $\operatorname{rod}=3$, Lavender $\operatorname{rod}=4$, 
Yellow rod=5, Dark Green rod=6, Black rod=7, Brown rod=8, Blue rod=9 and Orange rod=10. Cuisenaire rods can be used for equations, fractions, additions, subtractions, probabilities and statistics.

\section{Pattern Blocks:}

Pattern blocks are one centimetre thick multicoloured blocks that come in six shapes such as hexagon, squares, trapezoids, triangles, parallelograms and rhombi. Each shape is a different colour. They are used for fractions, patterns, geometry, symmetry, addition, multiplication, equations and ratios.

\section{Unifix cubes:}

They are colourful, interlocking cubes that link in only one way. They come in ten solid colours that make them quite visual for demonstrations and easily allow for patterning and sorting. Unifix cubes can be used for addition, subtraction, multiplication, division, patterns, fractions, equations and place value.

\section{METHOD}

This segment of the study looked at the research design, population, sample, instrumentation, data collection tools as well as validity and reliability of the test instrument.

\section{Research Design}

The appropriate research design for this study was pretest-posttest control group design. The design model is as shown below (Fig. 2):

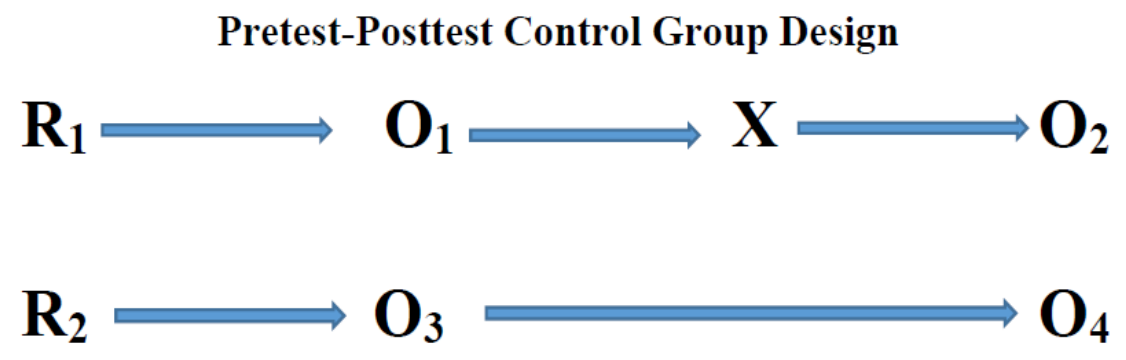

Figure 2: Pretest-Posttest Control Group Design

\section{Research Area}

St. Mary's Seminary Senior High School was the study area for this research study. It is a singlesex school with a population of 1004 boys. It is located at Lolobi-Kumasi in Likpe West Circuit in the Hohoe Municipality of the Volta region in Ghana. The major occupations of the people of LolobiKumasi are farming and fishing.

\section{Population of Study}

The target population of this study consisted of all second-year Senior High School students in the Hohoe Municipality. The experimental and control groups of 35 students each were used for the study. The age range of the students was 15 to 18. St. Mary Seminary Senior High School is one of the four-second cycle schools in the Hohoe Municipality in the Volta Region of Ghana. It is situated four Kilometers north of Hohoe. The school also had a teaching staff strength of 40 at the time of conducting this research.

\section{Sample and Sampling Techniques}

The sampling technique used in this study was purposive sampling. This refers to the type of sampling technique where a particular sample or group is expressly selected with a definite purpose based on the evidence available. The two (2) General Arts classes (2A1 and 2A2) took a pre-test, and the low achievers from each class were combined and randomly assigned to control and ex perimental 
groups and their results tabulated for further analysis. The Ministry of Education and Sports (MOESS, 2007) suggested that system of linear equations be taught in the second year of the Senior High School mathematics course schedule.

\section{Instrument for Data Collection}

The research instruments adopted by the researchers for the study were pre-test and post-test instruments as well as interview and questionnaire administered to students and teachers respectively to assess the effectiveness of the research.

\section{Pre-test}

A pre-test on a system of two linear equations was given to the two (2) General Arts classes who were classified into experimental and control groups. The pre-test was made up of eight (8) questions. The first four (4) questions were based on the formation of mathematical statements from word problems. Questions 5 to 8 were based on the students' ability to use the substitution method to solve the mathematical statement in a system of two linear equations.

Each student $w$ as given a printed question paper and answer sheets. The duration for the pre-test was fifty (50) minutes. Answers of students to the pre-test were marked based on a prepared marking scheme. The researchers critically examined (evaluated) the wrong answers given by the studen ts to find out the possible causes. Discussions were held with the students to find out why they answered some questions the way they did.

There $w$ as also an interview for students to determine the effectiveness of the use of the Algebraic tiles in helping them solve a system of two linear equations.

A questionnaire was also administered to the teachers who teach mathematics at the school with the emphasis on the solving system of two linear equations.

\section{Intervention}

The use of the Cuisenaire rods to solve a linear system of equations was the intervention in this research. For illustration, consider the example below:

Question: Solve the system of linear equations below by the method of substitution using algebraic tiles

$$
\begin{aligned}
& 3 x+4 y=2---------------- \text { equation (1) } \\
& x-4 y=6 \text {-------------------equation (2) }
\end{aligned}
$$

\section{Solution:}

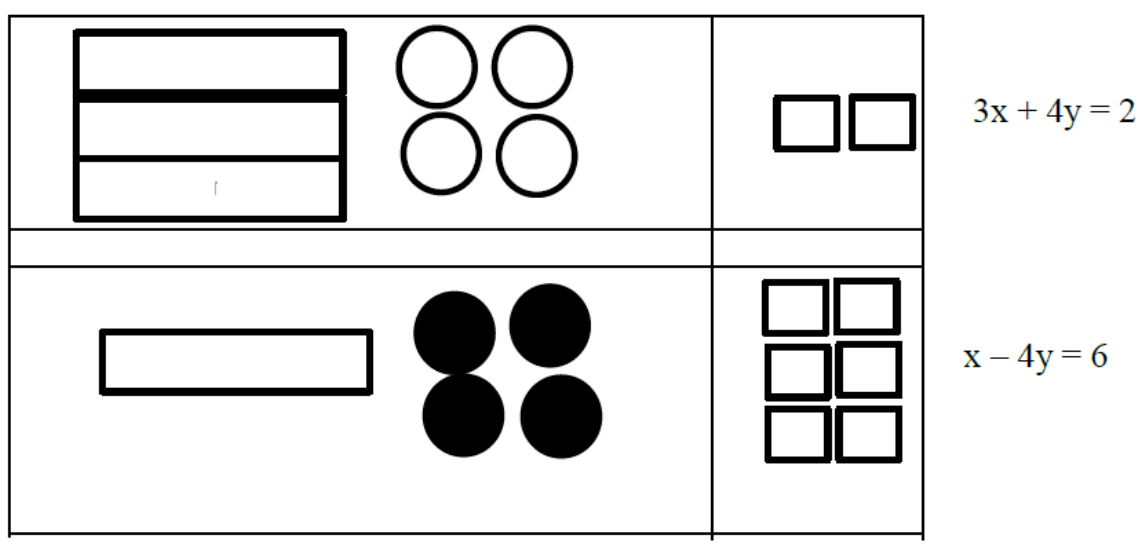

Solve for $\mathrm{x}$ in equation (2) 


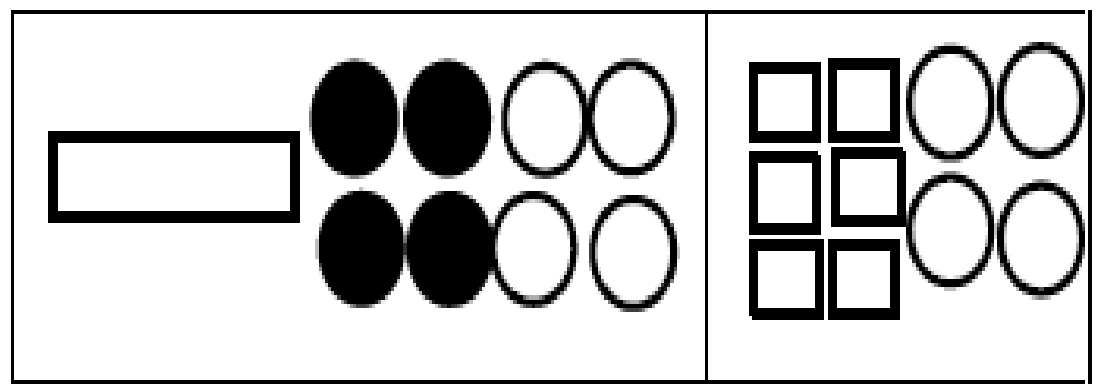

Solving for " $\mathrm{x}$ " we add $4 \mathrm{y}$ to each side of the equation (2) making it: $x-4 y+4 y=6+4 y$

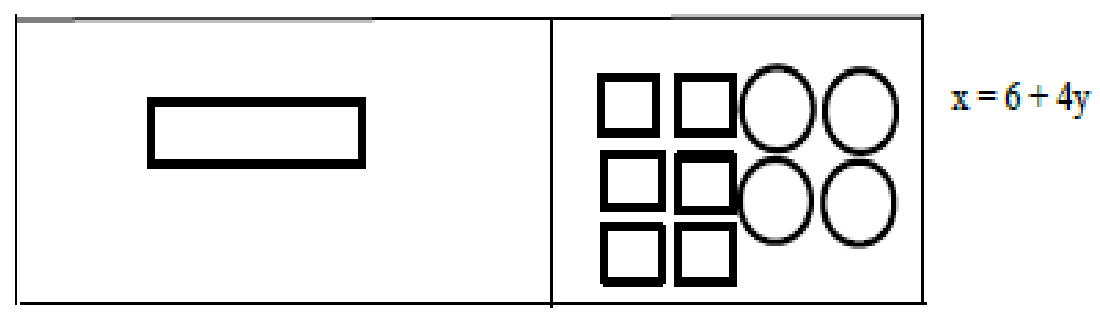

Since $-4 y+4 y$ will be equal to zero, $\quad x=6+4 y$

Substitute $6+4 y$ for $x$ in $3 x+4 y=2$ in equation (1) above, we have

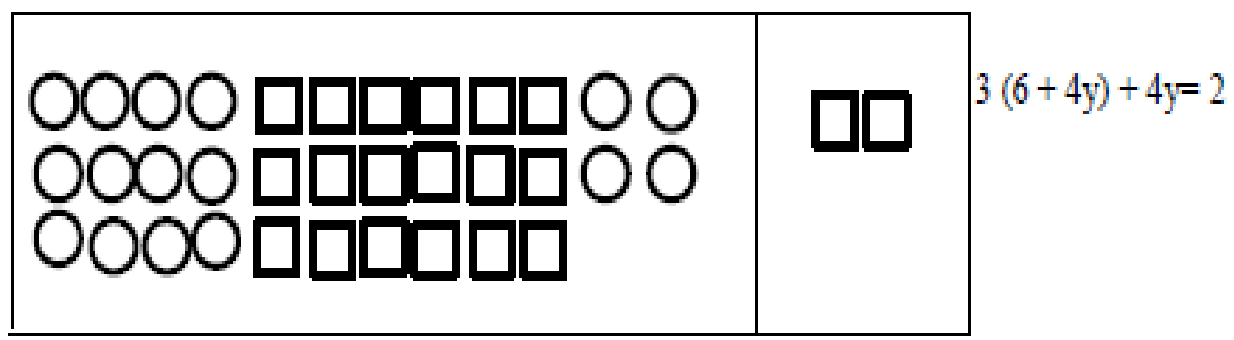

This produces $18+12 y+4 y=2$, which is the same as $16 y+18=2$

We add $(-18)$ to each side of the equation 16y $+18+(-18)=2+(-18)$

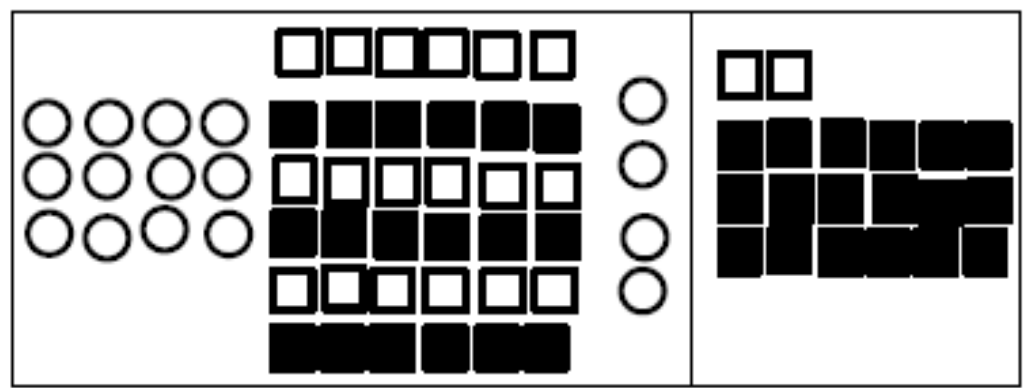

We therefore subtract 18 from each side of the equation and obtained; 


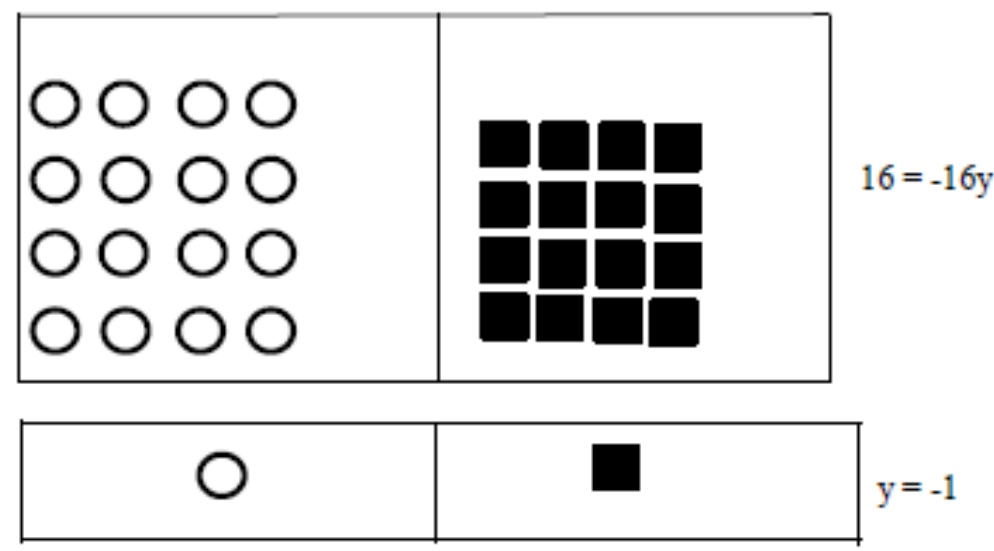

Substitute $y=-1$ in $3 x+4 y=2$
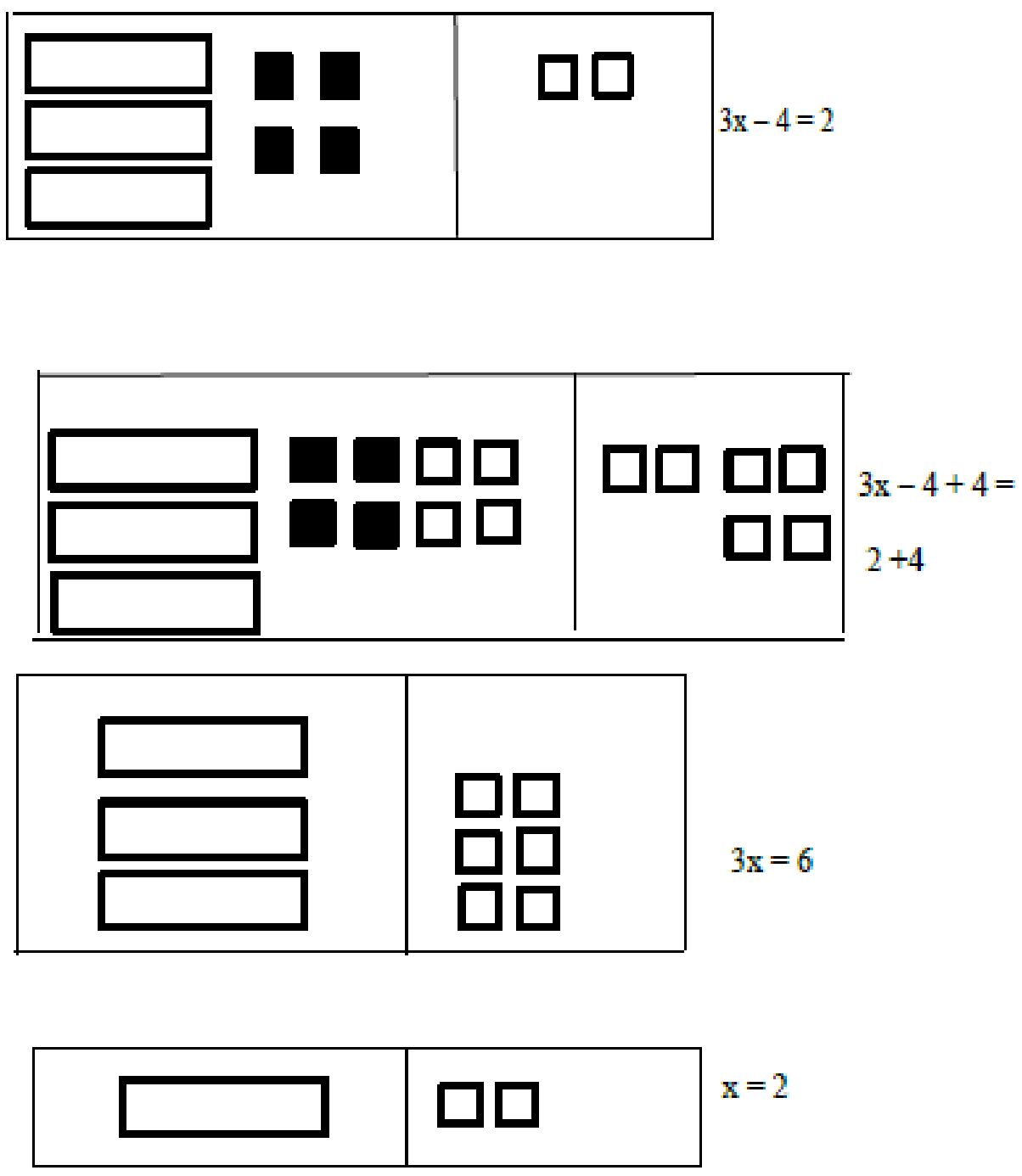

Therefore, the solution is $\mathrm{x}=2, \mathrm{y}=-1$

At the intervention phase, the researchers applied the algebraic tiles known as manipulatives for the experimental group whereas the control group received just the traditional method of teaching on the same topic. The researchers used the algebraic tiles model to address the lack of conceptual understanding in solving system of two linear equations with the experimental group. During the intervention stage, the students were exposed to strategies, opportunities and responses to what they were doing. The intervention period took four weeks of two mathematics sessions a w eek. 


\section{Post-test}

After the intervention, a post-test was carried out to find out how far the intervention had helped students to improve their performance. The post-test administered to the students had the same level of difficulty and the same number of questions like the pre-test though the questions were not the same.

\section{Validation of Instrument}

To ensure the validity and reliability of the instrument, it was pilot tested in another Senior High School with similar characteristics as the one in the study. The Cronbach's alpha for the pre-test was found to be $\mathbf{0 . 7 8}$, and that for the post-test was $\mathbf{0 . 8 1}$, and these values were high enough to attest to the reliability of the tests.

\section{Method of Data Collection}

The data collected in the pre-test and post-test of the control and experimental groups were recorded and analyzed for sampled means and standard deviations. An intervention implementation plan in which the Algebraic tiles were used to help students overcome their difficulties in solving system of two linear equations was put in place.

A questionnaire for mathematics teachers and interview for students were conducted to ascertain the effectiveness of the Algebraic tiles in helping students to overcome their difficulties in solving system of two linear equations.

\section{Method of Data Analysis}

The data collected were analyzed both quantitatively and qualitatively. The pre-test and post-test data were analyzed using both descriptive and inferential statistics. In the descriptive statistics, the minimum and the maximum scores of the sample mean scores and standard deviations for both the pre-test and post-test were analyzed. For further analysis of data, inferential statistics were used to project the paired sample scores of the samples to determine whether there was a significant improvement in the students' performances in solving a system of two linear equations after the intervention.

\section{FINDINGS}

The design of the research was to help improve students understanding in solving a system of two linear equations using the algebraic tiles model. The test analysis used the pre-test and post-test scores in analyzing the data. The analysis of the data is divided into two parts. The first part used descriptive analysis and the second part used inferential analysis. The sequence of the presentation and the discussion of the results obtained in this study were discussed by the research questions formulated for the study.Table 1 below is a descriptive summary of the pretest results administered to the experimental group. It shows the number of students who got each question wrong at the pretest stage and those who got it right.

\section{Summary of Pretest Scores Administered to the Experimental Group Table 1: Pretest Results of Questions (1 to 8)}

\begin{tabular}{cll}
\hline $\begin{array}{l}\text { Question } \\
\text { Number }\end{array}$ & $\begin{array}{l}\text { Wrong Answer } \\
\text { (Pre-test) }\end{array}$ & $\begin{array}{l}\text { Correct Answer } \\
\text { (Pre-test) }\end{array}$ \\
\hline 1 & $23(65.7 \%)$ & $12(34.3 \%)$ \\
2 & $26(74.3 \%)$ & $9(25.7 \%)$ \\
3 & $24(68.6 \%)$ & $11(31.4 \%)$ \\
4 & $31(88.6 \%)$ & $4(11.4 \%)$ \\
5 & $25(71.4 \%)$ & $10(28.6 \%)$ \\
6 & $23(65 \%)$ & $12(34.3 \%)$ \\
7 & $27(77.1 \%)$ & $8(22.9 \%)$
\end{tabular}


Table 2 below is also a summary of the results of the posttest administered to the same experimental group after the intervention. The table shows a sharp decline in the number of students who got each question w rong compared to the Table 1.

\section{Summary of Posttest Scores Administered to the Experimental Group}

Table 2: Posttest Results of Questions (1 to 8)

\begin{tabular}{lll}
\hline Question & $\begin{array}{l}\text { Wrong Answer } \\
\text { (Posttest) }\end{array}$ & $\begin{array}{l}\text { Correct Answer } \\
\text { (Posttest) }\end{array}$ \\
\hline 1 & $9(25.7 \%)$ & $26(74.3 \%)$ \\
2 & $11(21.4 \%)$ & $24(68.6 \%)$ \\
3 & $5(14.3 \%)$ & $30(85.7 \%)$ \\
4 & $10(28.6 \%)$ & $25(71.4 \%)$ \\
5 & $8(28.6 \%)$ & $27(77.1 \%)$ \\
6 & $10(65 \%)$ & $25(71.4 \%)$ \\
7 & $13(37.1 \%)$ & $22(62.9 \%)$ \\
8 & $16(45.7 \%)$ & $19(54.3 \%)$ \\
\hline
\end{tabular}

Table 3 is a descriptive summary of the results of the pretest administered to the control group of 35 students. The table shows the number of students who got each question wrong or right at the pretest stage.

Analysis of Results of Pretest Administered to the Control Group

Table 3: Pretest Results of Questions (1 to 8)

\begin{tabular}{lll}
\hline Question & $\begin{array}{l}\text { Wrong Answer } \\
\text { (Pre-test) }\end{array}$ & $\begin{array}{l}\text { Correct Answer } \\
\text { (Pre-test) }\end{array}$ \\
\hline 1 & $25(71.4 \%)$ & $10(28.6 \%)$ \\
2 & $20(57.1 \%)$ & $15(42.9 \%)$ \\
3 & $29(82.9 \%)$ & $6(17.1 \%)$ \\
4 & $18(51.4 \%)$ & $17(48.6 \%)$ \\
5 & $25(71.4 \%)$ & $10(28.6 \%)$ \\
6 & $26(74.3 \%)$ & $9(25.7 \%)$ \\
7 & $24(68.6 \%)$ & $11(31.4 \%)$ \\
8 & $30(85.7 \%)$ & $5(14.3 \%)$
\end{tabular}

Table 4 is a summary of the results of the posttest administered to the Control group. The table shows the number of students who got each question w rong or right.

Analysis of Posttest Scores Administered to the Control Group

Table 4: Posttest Results of Questions (1 to 8)

$\begin{array}{lll}\text { Question } & \begin{array}{l}\text { Wrong Answer } \\ \text { (Posttest) }\end{array} & \begin{array}{l}\text { Correct Answer } \\ \text { (Posttest) }\end{array}\end{array}$




\begin{tabular}{lll}
\hline 1 & $20(57.1 \%)$ & $15(42.9 \%)$ \\
2 & $18(51.4 \%)$ & $17(48.6 \%)$ \\
3 & $26(74.3 \%)$ & $9(25.7 \%)$ \\
4 & $15(42.9 .1 \%)$ & $20(57.1 \%)$ \\
5 & $23(65.7 \%)$ & $12(34.3 \%)$ \\
6 & $24(68.6 \%)$ & $11(31.4 \%)$ \\
7 & $22(62.9 \%)$ & $13(37.1 \%)$ \\
8 & $25(71.4 \%)$ & $10(28.6 \%)$ \\
\hline
\end{tabular}

\section{Inferential Analysis of Pre-test and Posttest Scores for the Experimental Group}

The statistical test $w$ as set at $\mathrm{P}<0.05$. Table 5 indicated the mean, standard deviation and standard error of the mean of the paired samples. The mean score of the pre-test was 30.429 , and that of the post-test was 60.771 .

Table 5: Paired Sample Statistics of Pre-test and Post-test Scores of 35 Experimental Students

\begin{tabular}{llcccc}
\hline & & Mean & N & Std Deviation & Std Error Mean \\
\hline Pair 1 & Pre-test score of respondents & 30.429 & 35 & 12.885 & 2.178 \\
& Post-test score of respondents & 60.771 & 35 & 19.557 & 3.306 \\
& & & & & \\
\hline
\end{tabular}

\section{Inferential Analysis of Pretest and Posttest Scores for the Control group}

The statistical test $\mathrm{w}$ as set at $\mathrm{P}<0.05$. Table 6 below indicated the mean, standard deviation and standard error of the mean of the paired samples. The mean score of the pre-test was 32.514 , and that of the post-test was found to be 47.771

Table 6: Paired Sample Statistics of Pre-test and Post-test Scores of 35 Control Students

\begin{tabular}{clcccc}
\hline & Mean & N & Std Deviation & Std Error Mean \\
\hline Pair 2 & Pre-test score of respondents & 32.514 & 35 & 12.514 & 2.115 \\
& Post-test score of respondents & 47.771 & 35 & 89.061 & 15.054 \\
& & & & \\
\hline
\end{tabular}

Testing the Hypothesis for the Experimental and Control Group

Table 7 shows the t-test analysis of the null hypothesis which states that "there is no significant difference in the mean scores of students before and after the introduction of algebraic tiles" at $\alpha=0.05$ level of significance.

$$
\text { Null Hypothesis } \quad H_{O}: \mu_{1}=\mu_{2}
$$

Alternative Hypothesis $H_{a}: \mu_{1} \neq \mu_{2}$

Table 7: Paired Samples Test of Pre-test and Post-test Scores of 35 Students (Experimental and control)

95\% Confidence Interval of the

Difference

Std Std Error

Mean Deviat Mean Lower Upper $\mathrm{T}$ df Sig

ion 


\begin{tabular}{|c|c|c|c|c|c|c|c|c|c|}
\hline Pair & Pre-test score & & & & & & & & \\
\hline \multirow[t]{2}{*}{1} & $\begin{array}{l}\text { of } \\
\text { respondents - }\end{array}$ & - & 25.742 & 3.959 & -39.185 & - & - & 34 & .000 \\
\hline & $\begin{array}{l}\text { Post- } \\
\text { test score of } \\
\text { respondents }\end{array}$ & 30.343 & & & & 21.500 & 6.973 & & \\
\hline \multirow{3}{*}{$\begin{array}{l}\text { Pair } \\
2\end{array}$} & Pre-test score & & & & & & & & \\
\hline & $\begin{array}{l}\text { of } \\
\text { respondents }\end{array}$ & - & 84.521 & 15.202 & -44.291 & 13.777 & - & 34 & 0.293 \\
\hline & $\begin{array}{l}\text { Post-test } \\
\text { score of } \\
\text { respondents }\end{array}$ & 15.257 & & & & & 1.068 & & \\
\hline
\end{tabular}

Decision: The pair 1 sample test analysis of the data yielded the value of $p=0.000$.

The test statistics $w$ as set at $\mathrm{P}<0.05$. Since $\mathrm{P}$ is less than 0.05 , the level of significant; we failed to accept the Null Hypothesis and accordingly accept the Alternative Hypothesis. Also, since the pair 2 sample test analysis of the data yielded value of $\mathrm{P}=0.293$, which is greater than the level of significant (0.05), we accept the null and reject the alternative hypothesis.

\section{RESULT, DISCUSSION, AND SUGGESTIONS}

The analysis of the result enables the researchers to find out the level of improvement of students understanding of a system of two linear equations using the substitution method.

\section{Research Question 1:}

How can the use of Algebraic Tiles bring about effective learning outcome in solving a system of two linear equations?

When the interventional period $w$ as for the analysis of the mean, standard deviation and the $t$ test score supported the fact that, performance in equations can be improved if teachers incorporate the use of Algebraic Tiles Model in their teaching in the classrooms. The post-test mean score of 24.750 (Standard deviation of 3.2842) is significantly higher than the pre-test mean score of 8.875 (Standard deviation of 3.0443).

"Reluctant" learners who previously did not do the work due to their attitudes began to participate in the problem-solving process when Algebraic tiles were being used. The students in the experimental sample realized that instead of competing for the right answers, they should rather learn how to share their problem-solving ideas and answers with each other

In another reaction, students discovered during the intervention that there are often several correct ways of finding a solution to a problem. This finding also confirms some of the earlier findings and assertion by researchers such as Clements (1999), who hold the view that teachers who employ concrete materials in their teaching usually outperform those who do not use them. This finding also shows that students' attitude tow ards algebra improves when they are taught using semi-concrete materials such as algebraic tiles model. The algebraic tiles model as a manipulative semi-concrete material is therefore useful and offers the students the necessary skills in algebra.

\section{SUMMARY OF FINDINGS}

The topic system of two linear equations sounded familiar to most students though they still have difficulties in solving it. The statistical difference showed that the intervention tools Algebraic tiles model used had improved student's algebraic knowledge under the study. Nevertheless, some students could read, understand and accept challenging questions but become confused when translating the story problem to mathematical statements and use the substitution method to solve mathematical statements. The research revealed that students did not know that they could learn better from their classmates until the intervention stage. The intervention helped students develop a more positive attitude tow ards equations and mathematics as a whole because they were more excited as they could easily answer challenging questions and reach sound conclusions. Other factors gathered 
from the findings included the teachers' systematic presentation of the topic to the students. Finally, the vital role of algebra for that matter system of two linear equations cannot be overstated since it covers most of the topics in mathematics and other subjects.

\section{Recommendations}

The study examined the benefits of the Algebraic tiles model in the teaching and learning of system of two linear equations. Based on the results of this study the researcher has these recommendations and suggestions for further studies:

1. This study had samples from St. Mary Seminary Senior High School Form 2 students. This indicated that there is the need for future studies in other Schools.

2. This study, as well as other previous studies, concluded that there was a significant effect on mathematics achievement when algebraic tiles are used in teaching mathematics because it serves as a link between concrete and abstract symbolic representations of mathematical ideas (Capps \& Pickreign, 1993). It is therefore recommended that more emphasis should be laid on the use of Algebraic tiles in teaching the topic at the S.H.S level.

3. Students should be made to solve a lot of problems practically in class instead of the theoretical approach.

4. Cooperative and discovery learning strategies should be encouraged in teaching concepts in the system of linear equations to make the lesson more practical as possible.

5. Finally, appropriate courses need to be introduced in the Colleges of Education for the training of teachers in the skills of designing, developing and applying the Algebraic tiles as well as other concrete materials in teaching system of two linear equations at the basic level of education.

\section{REFERENCES}

Afach, A. S., Kiw an E., \& Semaan, C. (2018). How to enchance on bullying for Special Needs Students using "Edpuzzle" a web 2.0 tool. International Journal of Educational Research Review. 3(1): 1-7

Ameron H., Lewis, B. A., \& Kirkland, L. (2011). Manipulatives: When they are useful? The Journal of Mathematical Behaviour, 20 (1), 21-31

Amponsah (2010, April 28). When will Ghana get represented at the Inter national Mathematical Olympiad? Ghanaw eb.com. Retrieved from:

https://www.ghanaweb.com/GhanaHomePage/features/When-will-Ghana-get-represented-at-theInternational-Mathematical-Olympiad-180836

Anamuah-Mensah, J., \& Mereku, D., K., (2005). Ghanaian JSS2 students' abysmal mathematics achievement in TIMMS-2003: A consequence of the basic school mathematics curriculum, Mathematics Connection 5, 1-13.

Austin, A. (2008). Educating integrated professionals: Theory and practice on preparation for the professoriate. San Francisco: Jossey- Bass.

Blum, M., K., (2002). Enhancement of students learning and attitudes tow ards mathematics through authentic learning experiences, unpublished dissertation, Curtin University of Technology, Australia.

Capps, L.R., \& Pickein, (1993), Language connections in mathematics: A critical part of mathematics instruction, Arithmetic Teacher, 9-12

Cockcroft, W.H. (1982). Mathematics counts. London: Her Majesty's Stationary Office.

Demirtas, Z., \& Aksoy, G. P. (2016). Investigation of pedagogical formation certificate program students' attitudes towards teaching profession in terms of some variables. International Journal of Educational Research Review, 1(1): 21-28

Duman, T. \& Karagöz, S. (2016). An evaluation of Turkish teacher education system compared to other models in different countries. International Journal of Educational Research Review (IJERE). 1(1):1-13

Eshun, B., A., (2004). Sex differences in attitude of students tow ards mathema tics in secondary schools, Mathematics Connection, 4:1-13. 
Eshun-Famiyeh, J., (2005). Early number competencies of children at the start of formal education, African Journal of Educational Studies in Mathematics and Sciences 3(3), 21-31

Fletcher, J. A. (2005). Constructivism and mathematics education in Ghana. Mathematics Connection, 5:29-36.

Franser, D. W. (2013), Five tips for creating independent activities aligned with the common core state standards. Teaching Exceptional Children, 45 (6), 6-15

Fredua-Kw arteng,Y.(2005, January 8). Ghana Flunks at Math and Science: Analysis (1). Ghanaweb.

Gavor, M. (2015, August 20). Too many students are failing the WASSCE. GhanaWeb. Retrieved from https://www.ghanaw eb.com/GhanaHomePage/features/Too-many-students-are-failing-theWASSCE-376575

Heddens, J.W. (1997). Improving mathematics teaching by using manipulatives. Retrieved from http://www.fed.cuhk.edu.hk.

Kosko K.W., \& Wilkins J.L., (2010). Mathematical communication and its relation to the frequency of manipulative use. International Electronic Journal of Mathematics Education, 5 (2): 79-90

Lee, S. J. (2014). Early childhood teachers' misconceptions about mathematics education for young children in the United States. Early Education and Development, 8 (1), 111- 143

Lira J, \& Ezeife A.N. (2008). Strengthening intermediate level mathematics teaching using manipulatives: A theory-backed discourse. Academic Exchange Extra. Ontario: Academic Exchange-Extra

Maslen, G., Douglas, T., Kadosh, R. C., Levy, N., \& Savulescu, J. (2014). The regulation of cognitive enhancement devices. Extending the medical model. Journal of Law and the Biosciences, 1 (1), 68 - 93.

Milgram, R. J., \& Wu, H. S. (2008). The key topic in a successful math curriculum. Retrieved from $<$ http: // math. berkeley. Edu> (Retrieved on 14th May 2014)

Ministry of Education (2002) Meeting the Challenges of Education in the twenty first century: Report of the president's committee on review of education reforms in Ghana. Accra, Ghana.

National Council of Teachers of Mathematics. (2000). Principles and standards for school mathematics. VA: National Council of Teachers of Mathematics.

Retrieved from: https:/www.ghanaweb.com/GhanaHomePage/features/Ghana-Flunks-atMath- and-Science-Analysis-1-73002

Post, T. (1981). The role of manipulative materials in the learning of mathematical concepts. In selected issues in mathematics education (pp. 109-131). Berkeley, CA: National society for the study of education and national council of teachers of mathematics, McCutchan publishing corporation.

Steedly, K., Dragso, K., Arafeh, S., \& Luke, S. D. (2008). Effective mathematics instruction. Evidence for Education, 3 (1), $1-12$.

Törner G., \& Sriraman B., (2006). A brief historical comparison of tendencies in mathematics didactics/education in Germany and the United States, ZDM, 38(1), 14-21. 